\title{
Organizational Culture, KNOWledge AND COMPETENCES IN VIRTUAL ORGANIZATIONS
}

\author{
Anca Georgiana Costache (Stochitoiu), Cicerone Laurentiu Popa, \\ Tiberiu Dobrescu, Violeta Carmen Zaleschi (Negrea) \& Costel Emil Cotet
}
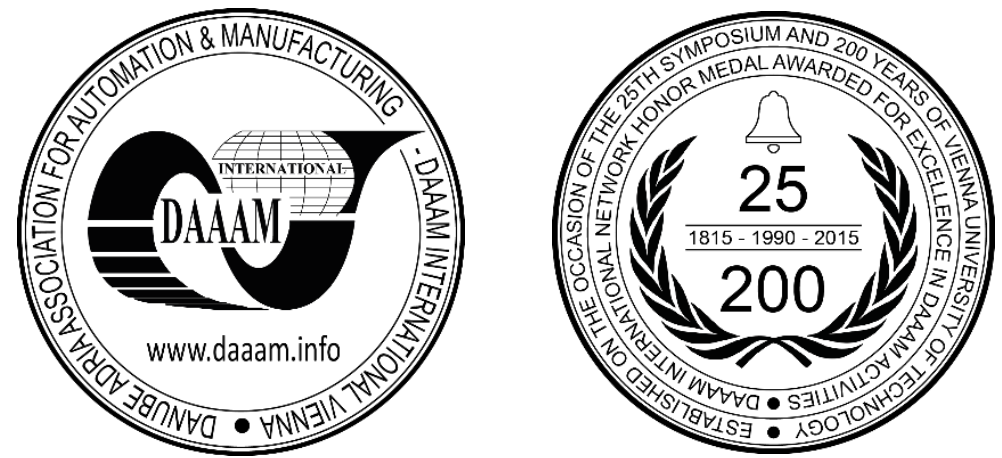

This Publication has to be referred as: Costache (Stochitoiu), A[nca] G[eorgiana]; Popa, C[icerone] L[aurentiu]; Dobrescu, T[iberiu] G[abriel]; Zaleschi Negrea, V[ioleta] C[armen] \& Cotet, C[ostel] E[mil] (2018). Organizational Culture, Knowledge and Competences in Virtual Organizations, Proceedings of the 29th DAAAM International Symposium, pp.0237-0242, B. Katalinic (Ed.), Published by DAAAM International, ISBN 978-3-902734-20-4, ISSN 1726-9679, Vienna, Austria

DOI: 10.2507/29th.daaam.proceedings.034

\begin{abstract}
The term „culture" speaks to an arrangement of qualities, moral standards, considering and acting models that are acknowledged by a collectivity and decide the given social gathering to act unmistakably from other social gatherings. The issue of association culture is all the time examined in connection to evolution. The normal origination is that a business enterprise culture strongly affects progress. An association culture that makes esteem assumes regard for individuals and administrations which not just fulfil the buyer's needs, yet in addition outperform them. Customary training has contributed significantly to the present levels of mechanical progress and innovative headway. Nonetheless, all together for advanced education to convey future ages with the correct arrangement of abilities and learning; a basic inquiry must be asked in regard to how advanced education organizations would be influenced by the fourth modern transformation and how the conveyance of training will be changed. There are diverse open doors accessible that will shape the part which can be embraced by advanced education in the fourth mechanical upset. Consolidating the quality of the customary advanced education with the expanding pattern speaks to essential strides to scale quality instruction that would change worldwide advanced education.
\end{abstract}

Keywords: virtual organizations; culture; competences; education; knowledge

\section{Introduction}

In this article will be debated the significance of organizational culture in advancement developments, knowledge basis and proper competences in relation with new requests. The goal is to feature the qualities of a culture hierarchical and its capacities in the new aggressive condition in which advancement is the key factor that guarantees upper hand. Authoritative culture can be deciphered as an outflow of social improvement of the venture. The expression "culture" in this way speaks to an arrangement of qualities, standards conduct, thought examples and activity that are found out and acknowledged by a what's more, that this social gathering is plainly separated from different gatherings social. The issue of organizational culture is breaking down regularly in its association with development. 
The broad idea is that hierarchical culture has a solid impact on advancement. As per this idea, the authoritative culture can bolster or thwart advancement forms. Featuring these marvels can be made suggestively with the assistance of promoter display. The significance of concentrate authoritative culture is given by the down to earth valences that this apparatus uses, increasingly frequently, in upgrading the association's execution. Prior to 2000, it was considered that for any organization there is a set of core competencies (general competencies, mandatory to all employees and directly related to the organization's field of work) and a set of skills specific to each job. These competencies are derived from the performance appraisal system, which contains both the competencies and their description, as well as the performance levels (scale and gradual descriptions) [1].

After 2000, the question arises as to whether a standard competency model for a particular post in different organizations, regardless of the industry in which the organization operates, can be used. There are authors who claim that for the same position, the same model of competence can be used, regardless of organization and industry. There are other authors who support faster the need for each organization to create their own competence models for their own positions. Studies conducted after 2000 have defined the existence of a third category of competences: so-called generic skills, skills that remain related to job specificity, regardless of organization and industry the organization operates (eg there are generic skills for the position of financial manager, developer, trainer, etc., independent of the organization and industry). To these generic skills are attached core competencies (organization specific) and specific skills (jobdependent) to complete the picture of a competency assessment system.

\section{The organizational culture in virtual organizations}

Most managerial theories believe the organization is before all, a social entity. On the other hand, "virtual" means an imitation, something that does not exist physically but possess all the features (or most of the "real" work, or rather, original). Thus, it is considered that before could talk about the "virtual" aspect, the organization should be addressed after a systemic vision, from a technical, operational perspective, with emphasis on the following constituent elements key:

- a set of economic processes;

- information and / or physical flows that generate trigger interactions between processes;

- mechanism for coordinating process execution and the flow of operations that make up them;

- roles-entities that bear responsibility coordinating and supervising operations and / or processes.

Replacing the social-human aspect with a vision role - oriented and flow - oriented technology operations as a basis for behavioural analysis, we can then talk to organizations virtual when: at least one roles is a software entity; the decisionmaking process takes place, if only partially, in an automated manner; interactions (or some of them) between processes are automatically established on the basis of a pre-established plan or ad-hoc negotiation. Ad-hoc chain reconfiguration capability of economic processes to serve applications highly personalized is the element descriptive key for virtual organizations. So, the virtual organization can be seen as an electronic version of the network organization. We can define the virtual organization as being that configuration of economic processes with a high degree of automation and belonging to a at least two different organizational entities, assembled ad hoc by a coordinator (broker) by negotiation on a free market with the purpose to work together for satisfaction of a request. When the assembly is reconfigured to serve a new request, we are talking about a new virtual organization.

Organizational culture represents a lifestyle, being the result of practices internal rules of conduct, values, aspirations and specific beliefs organizations. It is the one that confers the personality and identity of an organization. However, organizational culture does not completely control perceptions, thoughts and feelings the staff of the organization [2]. The longer the staff is in the organization, with the both the organizational culture will deeply influence your perceptions, thoughts, experiences the members of the organization, how they will respond in certain situations. The more an organization has its own stronger culture, the more it is mature and better defined, with a greater impact on employees, including one direct and direct impact on innovation and economic performance. Own model of organizational culture corresponds to a model of values and ways of behaviour that guides life in the organization. Strong companies do not rely solely on their rational instruments scientific management to achieve a certain productivity, a certain level of efficiency. They use organizational culture - deep beliefs, values communes and heroes embodying them, rituals and ceremonies to formulate and supports most strategies and policies. Starting from the way she dresses employees, even if there is no official uniform, to the way they are managed conflicts, everything bears the imprint of a unitary strategy that has the role of homogenize certain behaviours and positive outcomes and discourage others.

With the further development of a knowledge-based society, the concept of organizational culture becomes increasingly important, highlighting the powers of the "soft". At present, the organizational culture is no longer trend only under the pressure of the changes dictated by the information society and knowledge, but also the international competition or exchanges of values of the society [3]. 
Although each organizational culture represents a single system, there are some fundamental features specific to define it. They consider innovative organizational culture as a phenomenon by default, which is lived by the members of the organization. Innovative organizational culture is the result of a continuous process of learning. On the other hand, the organizational culture cannot be observed directly, because of a physical point of view, it does not exist. It is deduced indirectly as a system of values lived by the Community. Dissemination is informal and unofficial, taking different forms specific to each organization. Organizational culture, even if it is not visible directly, has profound implications on the economic performance of the organization. It shall submit a model of orientation which a strong influence on the daily activity. The cultural tradition is not taught consciously but is transmitted in the process of socialization of new members of the organization, through a series of default mechanisms. A culture of innovation is promoted by all the members of the organization and has deep roots in history, as an integral part of the tradition of the undertaking.

Its association with the learning process appears from the time in which certain problems are standardized because of the experience gained. By this classification of the problems is born a model with as examples, which governs the values of the entire organization. Based on this model leave the premise that every culture has a history based on its own development. Its beginnings were often unconscious, marked by powerful personalities who influenced by their specific attitudes models of the future behaviour of the staff of the undertaking. An Opinion is relevant to G. Hofstede, according to which the crop is of a collective phenomenon, because it is supported at least partially by people, who live or have lived in the same social environment, where it was learned [4]. The organizational culture bases stand in the national culture, since the rules, norms and values found in an organization have their origin in the rules, rules and the values promoted at the level of the national culture. Organizational culture not to be confused with the vision, mission or strategy of the organization. According to Hofstede's studies and management organizations are strongly influenced by the culture. Using Hofstede's model, we can identify at least two totally different perspectives about the approach of the situations of conflict.

American cultural model is by excellence conflict, characterized by individualism, enlarging self-interests and a strong dynamism at the level of the mentality, but at the same time dominated by exploiting the differences, contradictions and controversies the benefit of innovation and development. Another model, namely the Swedish and Japanese is characterized by a low degree of emotional reactivity. An interesting typology includes the crop type, the type of the academic team and type. Crop type has in the foreground formal leader who carries a thorough inspection. Crop type team requires the participation of all persons in a collective effort, for the common good and promote creativity and communication. Crop type academy puts an emphasis on personal development and attracting individual talents in areas of peak. The importance of organizational culture and the role played by the Community in the promotion of innovation may be highlighted by the analysis functions associated with the organizational culture. At a time once the globe is witnessing the most important exile crisis since the globe War II; education is being stressed over ever for those several refugees round the globe. Consistent with the report "Uncounted and Unacknowledged" regarding Syria's exile university students and teachers in Jordan, one in all the most challenges facing the availability of upper education to refugees and their inclusion in their host countries' instructional system is that the lack of official documents substantiating the tutorial levels noninheritable in their home countries. Having a digital identity that's trusty, transportable and secure, that stores a private info and might be used across countries particularly in cases of conflict eruption or natural disaster, would address this challenge [5].

The researcher's behaviour will indicate his/her identity and pursuit such behaviour, that is turning into a lot of attainable than ever through the fourth historic period, can make sure the verification of the identity; a significant step for enfranchisement. These efforts could lead on to the vision of "Global identity" which might extend on the far side the education sector to health sector et al and across countries [6].

Altering instruction is additional necessary than ever before. However, the challenges ahead got to be thought of to make sure effective and immediate transformation. With the reduced public financial backing for higher education; universities ought to assume strategically relating to ways to utilize their expertise in credentials, trust and identity to supply new services. What is more, instruction leadership must be less risk antipathetical particularly during this world of riotous amendment. Inequality would still be a priority for digital instruction since over four billion individuals square measure still offline while not access to the net. Most of these individuals square measure marginalized families UN agency sleep in developing countries with no access to an inexpensive education. Though digital instruction will be more cost-effective compared to different education choices, instruction establishments ought to consider the most effective ways that to reaching underserved populations wherever education will function a robust management and alter tool [7].

As people gain education from totally different universities, work numerous and world organizations and participate actively with totally different initiatives, his/her identity is not any longer tied to one organization as the paradigm of the Fourth Industrial Revolution explains that this evolution eliminates physical, digital and biological limits in the new industrial era [8]. 


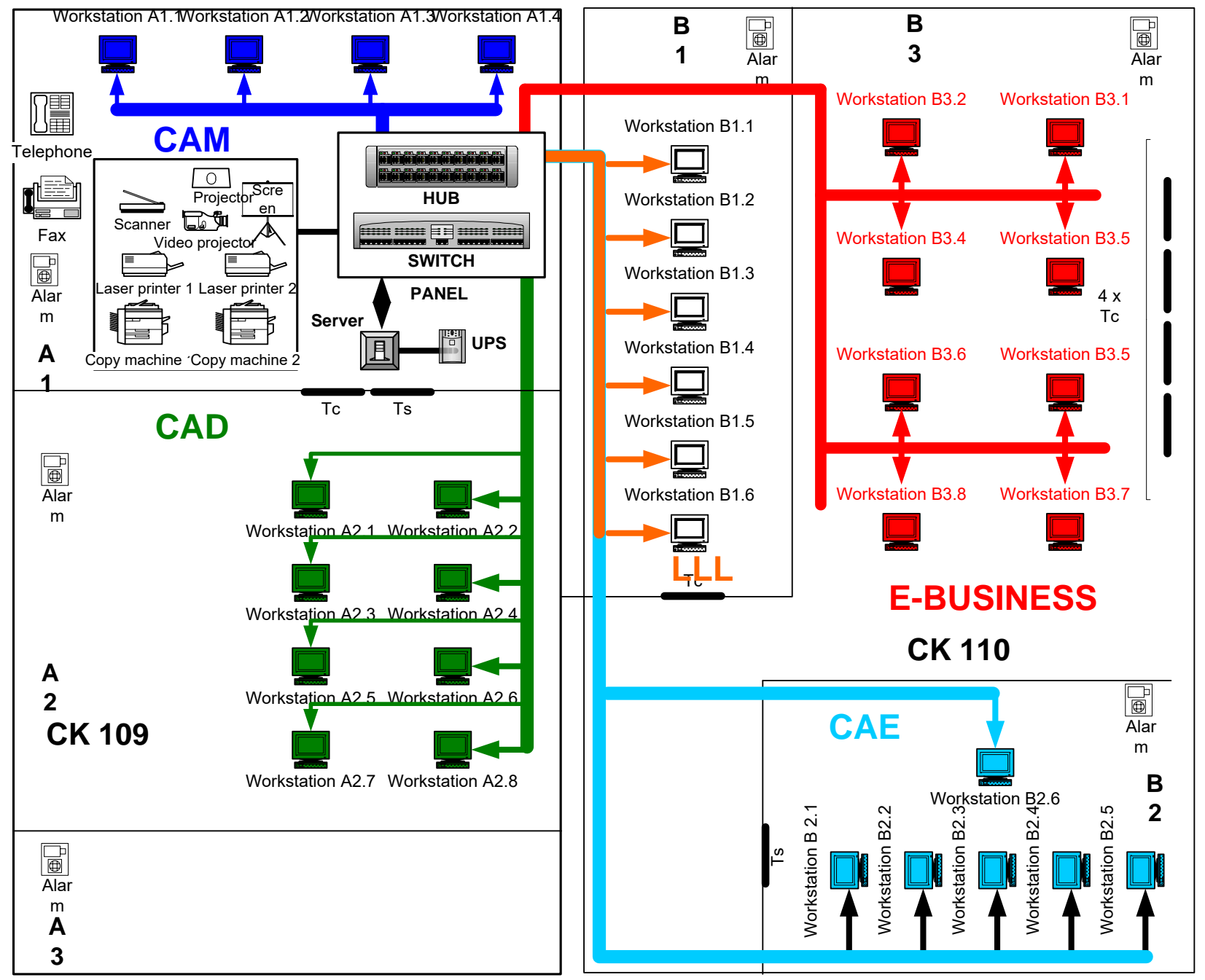

Fig. 1. The PREMINV training research and consulting experimental platform

The challenge behind this new industrial revolution is to produce educational frameworks able to integrate human resources with physical, cybernetic and Internet objects (IoT), Big Data and cloud computing, robotics, artificial intelligence and additive manufacturing systems into the Industry 4.0 paradigm (figure 1). Making identities supported each establishment one learns from or organization one works at might be terribly confusing and overwhelming; that raise the question of "What is our identity and wherever will we discover it?"

The trust placed in education establishments might be the driving force for education to be leading the creation of a world identity that's transportable across universities and organizations. Education isn't proprietary nor restricted to one ideology; its openness and long history of tryst makes it eligible to act as a keeper for safeguarding this identity and unendingly produce atmosphere for data and talent attainment.

As a primary step to the world identity, the necessity for federate identity is being recognized worldly; still, privacy remains a main concern for everyone within the digital world; wherever people would really like to take care of management over their identity. In contrast to industrial firms that aim to maximize management over ones' knowledge, federate identity and privacy management offer users way more management over what to be shared with smallest speech act of relevant knowledge. The shift for "Inter-federated Identity" is scaling the method of sharing entity information globally between totally different national federations with minimum barriers [9].

Risk, privacy and security square measure different challenges facing instruction. Collaboration, integration and positioning security method square measure key words for scaling instruction efforts and conveyance property. The complexness of the systems developed to satisfy the stress of the fourth historic period necessitate knowledge base and collaboration as a precondition for innovation. This is the time to raise whether or not the world instruction community can solely react to however the business world is shaping the Fourth historic period or if it'll be among the key players of shaping the Fourth Industrial revolution. 


\section{Conclusion}

For the companies established, radical innovations often meet significant barriers, because the question of existing structures and processes. The creative solving the problems requires certain spaces of manoeuvre, which is missing in the hierarchical organizations where there is a strong division of labour. For this reason, some companies to allow employees to reserve a specific part of the working time for the development of its own projects.

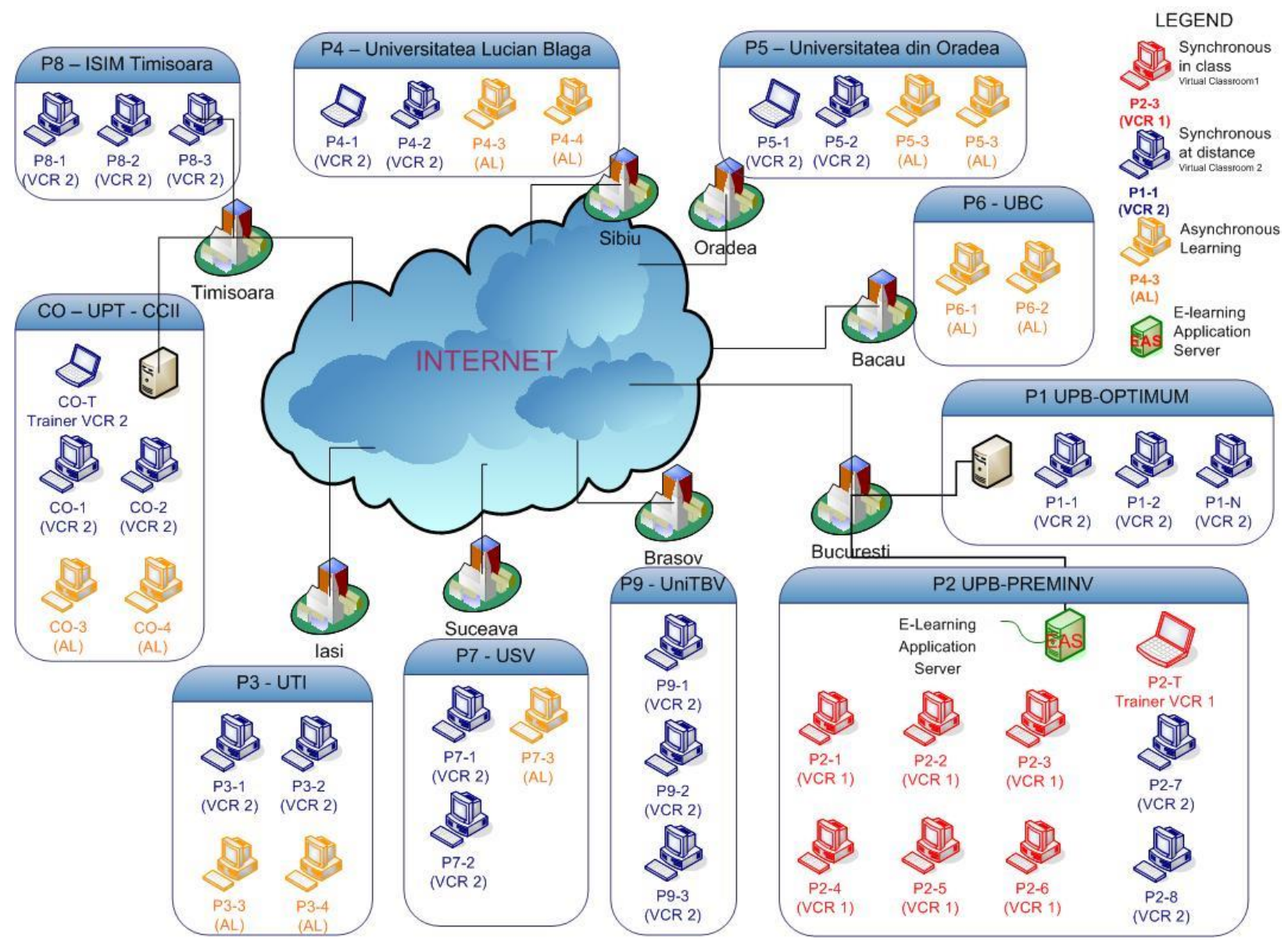

Fig. 2. A collaborative network

An organizational culture which creates an entrepreneurial type value implies the granting due respect for all persons, internal and external to the organization, and to promote the development of services, which not only to meet the needs of consumers, but they and beyond. This allows you to obtain competitive advantage, providing confidence and courage to take responsibility for the promotion of their own ideas by each employee. The main features of the organizational culture are oriented toward the future are represented by the desire to promote innovative solutions, the ability to identify and accept the mistakes and weaknesses and to analyse them with a view to the development of measures with innovative character.

The new concept of organizational culture facilitates innovation and the learning process, both by leveraging its own experiences, as well as the one existing in the other organizations performance at the local level or internationally. Universities emphasize their role in shaping future technology by being the testbeds for innovation and educating future generations according with the new technologies. For example in the netword presented below engineering services are delivered to SME through nine research centres based in universities, located in Bucharest and other cities, selected according to criteria related to men power, basic infrastructures know-how and traditions (figure 2). Now, such Branch are not devoted only to the delivery of information and of "first level" engineering consulting services, but also for the most sophisticated ones like management and administration services and consulting or design/production support services. The ease of use and lower costs of shared resources and services offered by such a network can create multiple facilities for companies, by helping them to use and value the newer ICT or digital opportunities. Ancient education has contributed greatly to the present levels of business evolution and technological advancement. However, so as for educational activity to deliver future generations with the proper set of skills and knowledge; an important question has got to be asked concerning however educational activity institutes would be tormented by the Fourth Industrial Revolution and the way the delivery of education is reworked. 


\section{References}

[1] 허지숙. (2017). Social Network Analysis of the Core Competencies of the Fourth Industrial Revolution on the Newspaper Articles : Focusing on in Engineering Students. Journal Of Engineering Education Research, Vol. 20, No. 5, pp. 50-58, DOI 10.18108/jeer.2017.20.5.50

[2] De Witte, K. \& Muijen, J. (2000). Organizational culture. Hove UK: Psychology Press.

[3] Lippert, R. \& Nyerki, E. (2011). The role of soft factors on the successful cooperation of clusters. Annals of DAAAM for $2011 \&$ Proceedings of the 22nd International DAAAM Symposium, Vol. 22, No. 1, ISSN 1726-9679, ISBN 978-3-901509-83-4, Editor Katalinic, B., pp. 1073-1074, Published by DAAAM International, Vienna

[4] Hofstede, G.; Hofstede, G. \& Minkov, M. (2010). Cultures and organizations : software for the mind - intercultural cooperation and its importance for survival, McGraw-Hill, ISBN 978-0071664189, New York, USA

[5] KimDaeSig. (2017). Identity and Role of Elementary Education in the Fourth Industrial Revolution Era. The Journal Of Educational Idea, Vol. 31, No.4, pp. 23-45, DOI 10.17283/jkedi.2017.31.4.23

[6] Allinson, C.; Chell, E. \& Hayes, J. (2000). Intuition and entrepreneurial behaviour. European Journal Of Work And Organizational Psychology, Vol. 9, No. 1, pp. 31-43, DOI 10.1080/135943200398049

[7] Oh,In-Tahk. (2017). The Fourth Industrial Revolution and the Tasks of Education. Journal Of Christian Education In Korea, Vol. 52, pp. 417-445. DOI 10.17968/jcek.2017..52.013

[8] Cotet, G.B; Balgiu, B.A \& Zaleschi, V.C. (2017). Assessment procedure for the soft skills requested by Industry 4.0, The 8th International Conference on Manufacturing Science and Education - MSE 2017 "Trends in New Industrial Revolution", MATEC Web of Conferences, Volume 121, Article Number 07005, eISSN: 2261-236X

[9] Paulova, I.; Vanova, J.; Rusko, M; Hekelova, E. \& Kralikova, R. (2017). Knowledge Managements for Improvement the Competitiveness of Organization, Proceedings of the 28th DAAAM International Symposium, ISSN 1726-9679, ISBN 978-3-902734-11-2, B. Katalinic (Ed.), pp.1221-1226, Published by DAAAM International, Vienna, DOI: 10.2507/28th.daaam.proceedings. 170 